\title{
Snodgraft Versus Snodgrass Repair of Primary Distal Hypospadias: A Comparative Study
}

\author{
Wael Omar Zeina ${ }^{*}$, Ahmed Medhat Zaki ${ }^{2}$, Osama Abdel-Ellah Al-Najjar ${ }^{2}$, \\ Ehab Abd El Aziz EI Shafei ${ }^{2}$ and Mohamed Abdel-Sattar Mohamed ${ }^{2}$
}

\author{
${ }^{1}$ Department of Pediatric Surgery, Benha Children Hospital, Egypt \\ ${ }^{2}$ Department of Pediatric Surgery, Faculty of Medicine, Ain Shams University, Egypt
}

*Corresponding author

\section{A B S T R A C T}

\section{Keywords}

Distal hypospadias;

Snodgrass repair,

Snodgraft repair,

Meatal stenosis,

urethrocutaneous

fistula

Article Info

\section{Accepted:}

16 April 2021

Available Online:

10 May 2021
Hypospadias is one of the most common congenital anomalies of the male genitourinary system. Snodgrass operation is a quiet popular technique used to repair distal and mid shaft defects. However, it carries increased risk of many complications such as meatal stenosis. Snodgraft repair using an inner preputial free graft is a proposed technique aiming to reduce the risk of complications. This study was carried out to compare between Snodgraft and Snodgrass techniques in the repair of distal hypospadias. The study included 60 cases of distal hypospadias that were admitted to the Pediatric Surgery department at Benha Children Hospital during the period from January 2017 to July 2020. Cases were divided into 2 groups; Group I: The Snodgrass group (30 cases) and Group II: The Snodgraft group (30 cases). The mean operative time was longer for patients in Group II than in Group I (75.47 \pm 9.25 minutes versus $50.07 \pm 7.28$ minutes). Postoperative urethrocutaneous fistula occurred in one patient (3.3\%) in each group. Meatal stenosis developed in 2 cases (6.7\%) in Group I versus 1 case $(3.3 \%)$ in Group II. Meatal recession occurred in 2 cases $(6.7 \%)$ in Group II. There was no significant difference in the complication rate among both groups. Snodgraft operation is more technically challenging and requires longer operative time than the original Snodgrass operation, so its indication should be tailored according to the patient condition. Both techniques have low complication rates. Therefore, in order to find out what truly is the better technique, larger sample size may be needed to favor one technique over the other.

\section{Introduction}

Hypospadias means atypical placement of the urethral meatus, which is ectopically located on the ventrum of the penis. Hypospadias may convey a range of abnormalities involving abnormal development of the corpora spongiosum. In more severe forms of the disease, the corpora spongiosum is absent resulting a perineal urethral opening (Moosa and AL-hallak, 2020). Proximal to the ectopic meatus there is a segment of hypoplastic 
urethra that is not surrounded by any spongiosum. The corpus spongiosum division marks the proximal limit of the malformation (Renaux-Petel et al., 2019).

In addition to abnormal meatal location, the classic presenting triad of hypospadias includes ventral curvature (chordee) and abnormal prepuce with excessive redundant skin hood on the dorsal penis (Nurhadi and Saputra, 2018).

Hypospadias is one of the oldest diseases described in the practice of medicine, it was first documented by Galen of Pergamon, the well-known physician of Roman emperors and gladiators in the second century who gave the condition its name (Maitra et al., 2019).

Since this initial description of the condition, hypospadias management has been the focus of a myriad of surgeons and till today there have been over 400 described operations for hypospadias repair together with thousands of publications. The anomaly continues to pose a challenge and there is a learning curve for every surgeon (Hadidi, 2017).

Hypospadias is the second most common congenital anomaly of the genitourinary system after undescended testes and it is the common estcongenital malformation of the penis (Van der Horst and De Wall, 2017).

The international incidence is 1 per 200 to 300 live male births per year (Shah et al., 2018). Up to $70 \%$ of the detected cases are mild, where the urethral opening lies close to its normal location and just below the glans (distal hypospadias) (Cripps et al., 2019).

Unfortunately, hypospadias etiology in the majority of patients remains unknown. Genetic and environmental factors are the main susceptibilities (Chang et al., 2020). Several other factors such as advanced maternal age, maternal obesity, premature delivery in addition to low-birth-weight babies and twins have all been observed to have a higher risk of occurrence of hypospadias (Chen et al., 2018).

Although hypospadias is not life threatening, it can result in functional abnormalities with urination, intercourse and sperm deposition (Van der Horst, 2017). Therefore, the main goals of management include reconstruction of the urethra with placement of the meatus at the tip of the glans to allow proper urinary stream as well as correction of the penile curvature to minimize sexual dysfunction and achievement of acceptable cosmetic results to reduce the psychosocial burden on the affected individual (Chan et al., 2020).

TIP repair was first introduced in 1994 and it has revolutionized the management of hypospadias. It has many advantages such as better cosmesis, meatus at the tip of the penis and straight phallus. It is considered the procedure of choice in management of distal hypospadias by many surgeons (Zain, 2017). Rational of the technique is to perform an incision in the urethral plate to permit tensionfree tubularization of the neourethra that later on undergoes healing (Keays and Dave, 2017).

However, the mechanism of healing of the incised plate is still debatable and many authors believe that it heals by epithelial creeping, which theoretically increases the incidence of complications because of healing by primary intention if allowed to contract (Salah et al., 2019).

Kolon and Gonzales published a new technique of one-stage urethroplasty with a dorsal inlay graft using inner preputial skin (GTIP) in 2000 (Abbas, 2018). They predicted the effectiveness of GTIP because the neourethra is not left with a large denuded surface that allows for possible scar formation. 
With insertion of a free preputial graft, the urethral plate could be preserved in an attempt to improve healing of the neourethra after TIP urethroplasty (Kishk et al., 2018).

\section{Materials and Methods}

After obtaining approval from the ethical committee at faculty of medicine, Ain Shams University (No IRB 0006379), this prospective randomized controlled study was conducted to include 60 cases of distal hypospadias that were admitted in the Pediatric Surgery department at Benha Children Hospital during the period from January 2017 to July 2020. Cases were divided randomly into 2 groups: Group I: The Snodgrass group (30 cases) and Group II: The Snodgraft group (30 cases). Patients with proximal hypospadias, disorders of sex development, sever chordae, micropenis, circumcised penis, previous hypospadias surgery were all excluded from the study.

\section{Surgical technique}

Intravenous antibiotic prophylaxis was given before the induction of anesthesia (cefotaxime $50 \mathrm{mg} / \mathrm{kg}$ iv), then caudal block was done to reduce the post-operative pain.

\section{Snodgrass surgical technique}

A traction suture using a 5-0 polyglactin was placed in the glans tip followed by a U-shaped incision at the limits of the urethral plate then degloving of the penile skin was done with care to preserve sufficient mucosal collar.

Dissection was made with glans wings mobilization and a relaxing incision was made in the midline within the meatus to the level of urethral nub in patients who underwent Snodgrass technique, and to the end of the plate in Snodgraft group. The neourethra was closed using 6-0 vicryl continuous subcuticular sutures and reinforced with interrupted subepithelial sutures over a 6 or 8 $\mathrm{F}$ stent and secured to the glans traction suture.

A local vascularized flap of dartos fascia either dorsal or ventral is fixed to cover the entire neourethra. The glans wings, submucosal collar and ventral shaft skin were then closed in the midline using interrupted simple 6-0 vicryl sutures. Finally, a gauze dressing was applied and the stent was left for 5-7 days (Figure.1).

\section{Snodgraft surgical technique}

The same steps of Snodgrass technique were applied to each case in addition to the following: A deep midline incision was made longitudinally in the urethral plate followed by harvesting a small free graft from the inner preputial skin with removal of excess fatty tissue. The main principle in harvesting a graft was to cover the entire incised area of the urethral plate by adequately measuring the size of the graft. Therefore, the length and width of the graft was affected by every change in the depth of the midline incision, urethral plate configuration and meatal location. The graft was fixed to medial edges and the base of the incised plate with interrupted $6 / 0$ polyglactin suture (Figure 2 ).

\section{Postoperative care}

The repair was done on an out-patient base and all the patients were discharged on the same day. After discharge, they received oral broad-spectrum antibiotic for the duration of the urethral catheter. They also received diclophenac sodium analgesics to decrease the post-operative pain. The dressing was removed after 2-3 days and the urethral catheter was removed after 5-7 days of the operation. 


\section{Follow up}

Follow up visits were scheduled weekly for the first month, then after 3 and 6 months later. Patients' caregivers were informed to attend the outpatient clinic if any voiding problems occurred. Patients were assessed for the presence of early or late complications in addition to observation of the following: meatal shape and position, shape of the glans, shape of the penile skin, general cosmetic appearance and voiding pattern.

Calibration of the neourethra is done using uretheral dilators after one month, three months and six months (figure 3 ).

The accepted cosmetic penile appearance was defined as a slit shaped meatus at tip of the glans with no stenosis, fistula or diverticulum with a straight penis that reaches both the surgeon and parent's satisfaction (figure 4 and figure 5).

Uroflowmetry was performed in four cases (two cases in the Snodgrass group and two cases in the Snodgraft group) to assess the urine stream as well as detect any complications.

Cystoscopic examination was done in two cases in the Snodgraft group to assess the status of the implanted graft as well as evaluate the urethral condition and detect any possible urethral stricture. The two cases showed viable in place graft with adequate urethral caliber.

\section{Statistical analysis}

Statistical analysis was done by SPSS v25 (IBM@), Chicago, IL, USA). Shapiro-Wilks test and histograms were used to evaluate the normality of the distribution of data. Quantitative parametric data were presented as mean and standard deviation (SD) and were analyzed by unpaired student t-test. Quantitative non-parametric data were presented as median and range and were analyzed by Mann Whitney-test. Qualitative data were presented as number and percent and were compared by chi-square $\left(\mathrm{X}^{2}\right)$ or Fisher's Exact test when appropriate. $\mathrm{P}$ value $<0.05$ was considered statistically significant

\section{Results and Discussion}

In this study, the age of cases ranged between 6 and 18 months with a mean value of (12.6 $\pm 3.64)$ in group I and a mean value of $(11.40$ \pm 3.10 ) in group II. The meatal position in cases of group I was distal penile in 21 cases (70\%), mid penile in 3 cases (10\%), coronal in 2 cases $(6.7 \%)$ and sub coronal in 4 cases $(13.3 \%)$. The position of meatus in group II was distal penile in 20 cases $(66.7 \%)$, mid penile in 2 cases $(6.7 \%)$, coronal in 3 cases $(10 \%)$ and sub coronal in 5 cases $(16.7 \%)$. The meatal position was insignificantly different between both groups ( $\mathrm{P}$ value $=0.946$ ). The urethral plate width ranged between 4 and 7 $\mathrm{mm}$ in group I with a mean value of $4.85 \pm$ $0.73 \mathrm{~mm}$, while the urethral plate width in group II ranged between 3.5 and $7 \mathrm{~mm}$ with a mean value of $4.57 \pm 0.75 \mathrm{~mm}$. The urethral plate width was insignificantly different between the two groups ( $p$ value $=0.145$ ). The urethral plate width after operation of cases ranged between 5.5 and $8.5 \mathrm{~mm}$ in group I with a mean value of $6.72 \pm 0.98 \mathrm{~mm}$, while the urethral plate width after operation of cases in group II ranged between 6 and $8.5 \mathrm{~mm}$ with a mean value of $7.15 \pm 0.70 \mathrm{~mm}$. The urethral plate width after operation was insignificantly different between the two groups (P value $=0.053)$.

The operative time ranged between 40 and 65 minutes in group I with a mean value of $50.07 \pm 7.28$ minutes, while the operative time in group II ranged between 58 and 90 minutes 
with median value of 77.5 minutes and a mean value of $75.47 \pm 9.25$ minutes. The operative time showed a significant difference between the two groups ( $\mathrm{P}$ value $<0.001)$.

The total complication were 3 cases $(10 \%)$ in group I and in 4 cases $(13.3 \%)$ in group II. The complication rate was insignificantly different between both groups.

The complications in group I were fistula in 1 case $(3.3 \%)$ and stenosis in 2 cases $(6.7 \%)$. The complications in group II were fistula in 1 case $(3.3 \%)$, stenosis in 1 case $(3.3 \%)$ and recession in 2 cases $(6.7 \%)$ Figure (6).

Duckett described hypospadias surgery as a humbling process, an intriguing task that often confounds the surgeon, highlighting the complex blend of art and science to perform a successful repair. And although there has been great progress since this description, there is still much work left to be done (Long and Canning, 2016).

The incredibly increasing abundance of proposed techniques to manage hypospadias represents unmistakable evidence that no such operation is flawless and still there is no worldwide agreement on any of the known surgical techniques.

As is true for all reconstructive procedures, the best chance of a good outcome is with the first operation. Certain factors like location of the meatus and the degree of proximal spongiosal hypoplasia, presence and degree of chordee, quality (width and depth) of the urethral plate, size of the glans, degree of ventral skin deficiency and penile length are all key factors for operative planning (Thakur, 2018).

Many authors prefer using the TIP technique advocating that it is versatile, highly standardized, and a learnable technique that provides favorable cosmetic outcome in addition to adequate functional short term and long term results (Springer et al., 2017).

While other authors report high incidence of complications as a result of gradual fibrosis of the neourethra that is reconstructed based on a raw area which heals causing narrowing of the segment (Abbas and Pippi Salle, 2018).

Another factor that threatens the popularity of Snodgrass technique is that some surgeons believe it is inappropriate for cases with narrow urethral plate $(<8 \mathrm{~mm})$.

They imply that the urethral plate needs to be augmented or substituted for further tubularization especially in cases with insufficient local tissue or unfavorable urethral plate, particularly after trials of previous hypospadias repair (Pan, 2017).

In the current study, we conducted a comparison between Snodgrass (TIP) technique and Snodgraft technique (GTIP) regarding preoperative, operative and postoperative parameters.

As regard to the achieved meatal shape after surgery, the majority of patients in our study (90\% of cases in Snodgraft group and up to $96.7 \%$ of cases in the Snodgrass group) eventually had an acceptable normal-looking penis with a slit shaped opening of meatus.

This matched the general consensus that successful hypospadias urethroplasty is defined to have a slit-like meatus at its tip, a functional urethra with normal stream (Zhang et al., 2020).

The operative time was one of the important comparative points in this study; we found out that there was statistically significant difference between the two study groups. This difference represents the time consumed in order to prepare and fix the graft. 
Table.1 Operative time (in minutes) in both groups

\begin{tabular}{|c|c|c|c|c|}
\hline & Proup I & $\begin{array}{c}\text { Group II } \\
(\mathbf{n = 3 0})\end{array}$ & P value \\
\hline $\begin{array}{c}\text { Operative time } \\
\text { (minutes) }\end{array}$ & Mean \pm SD & $50.07 \pm 7.28$ & $75.47 \pm 9.25$ & $<0.001$ \\
\cline { 2 - 5 } & Range & $40-65$ & $58-90$ & \\
\hline
\end{tabular}

Fig.1

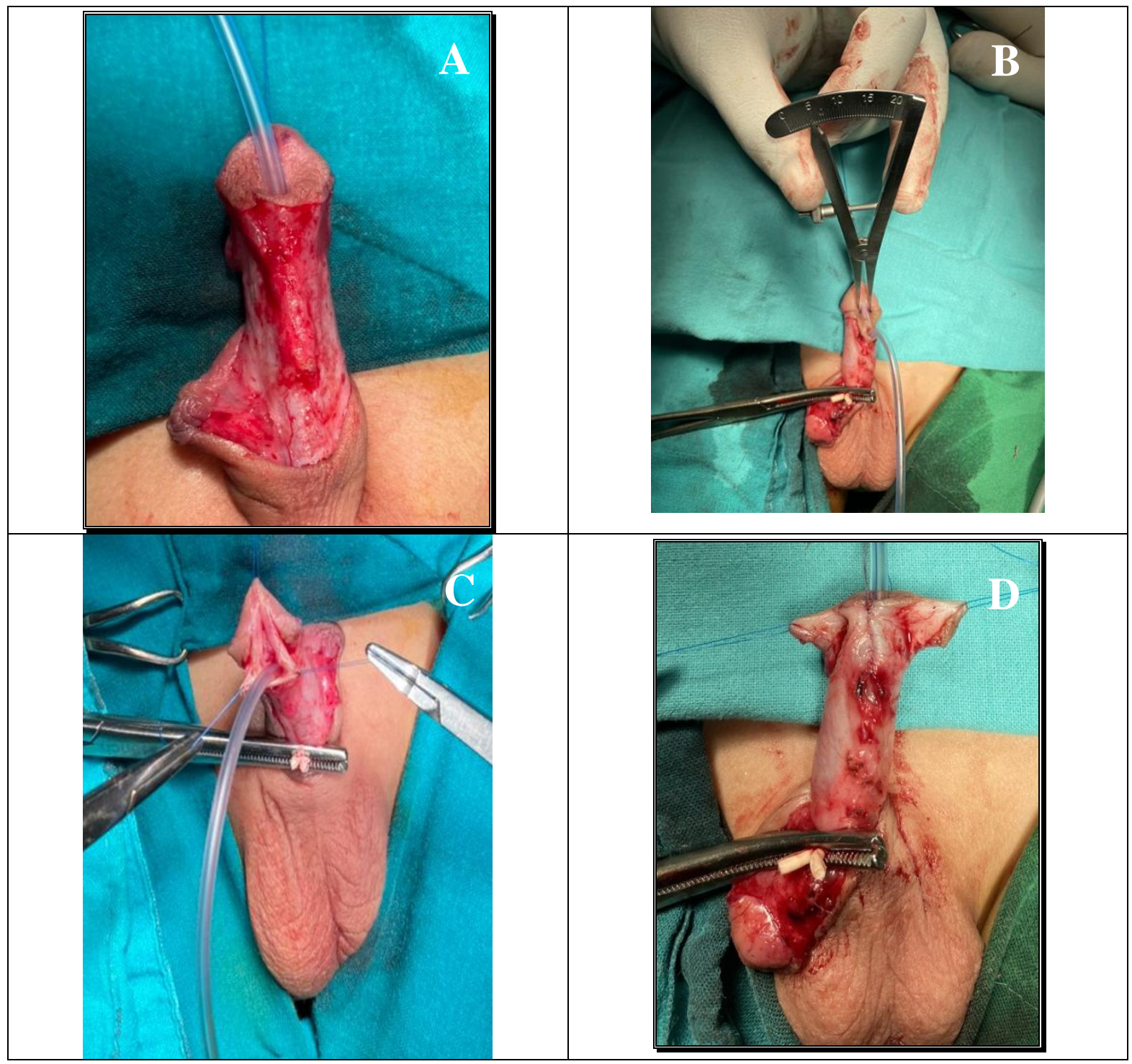


Int.J.Curr.Microbiol.App.Sci (2021) 10(05): 512-523
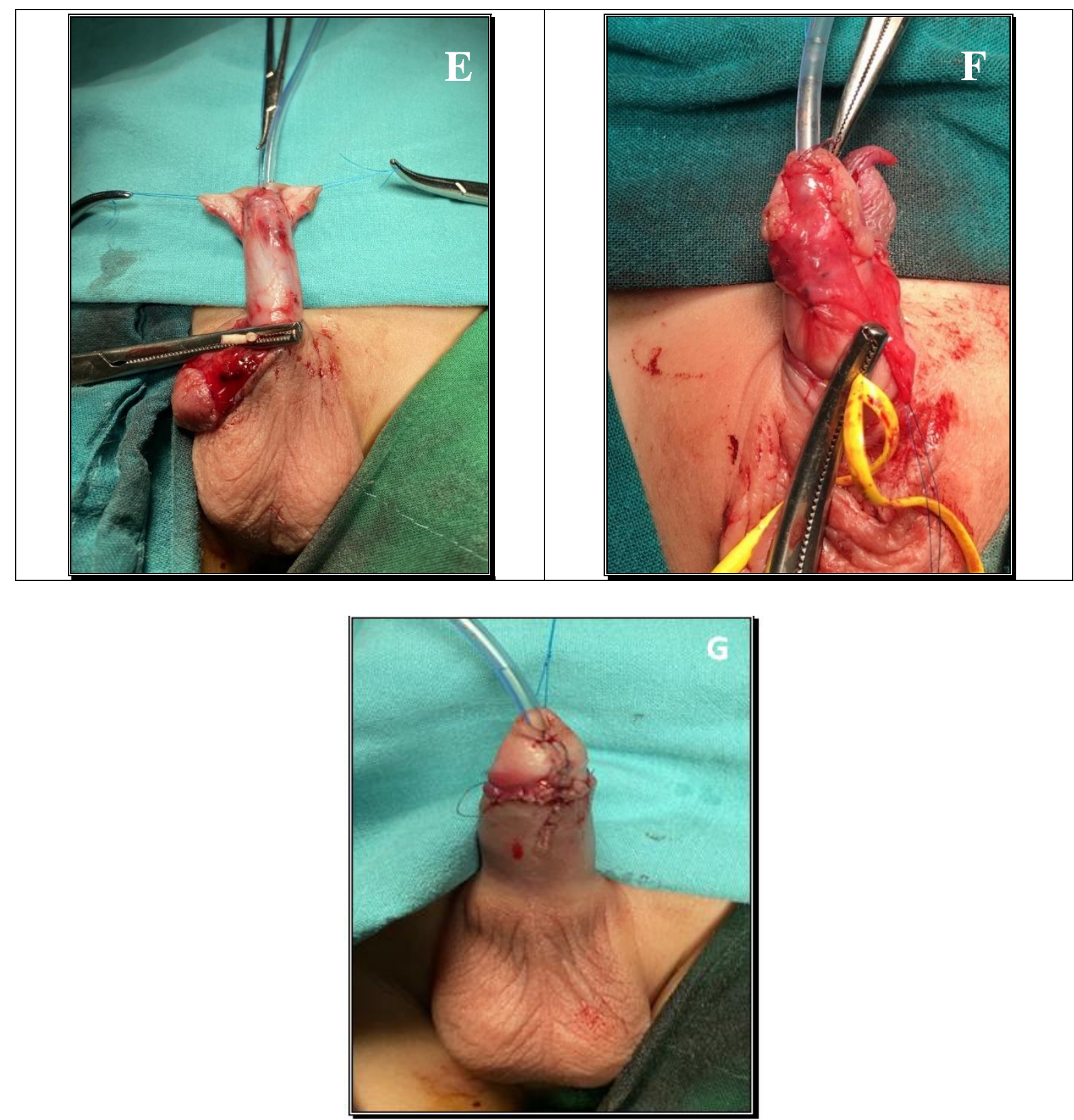
Fig.2

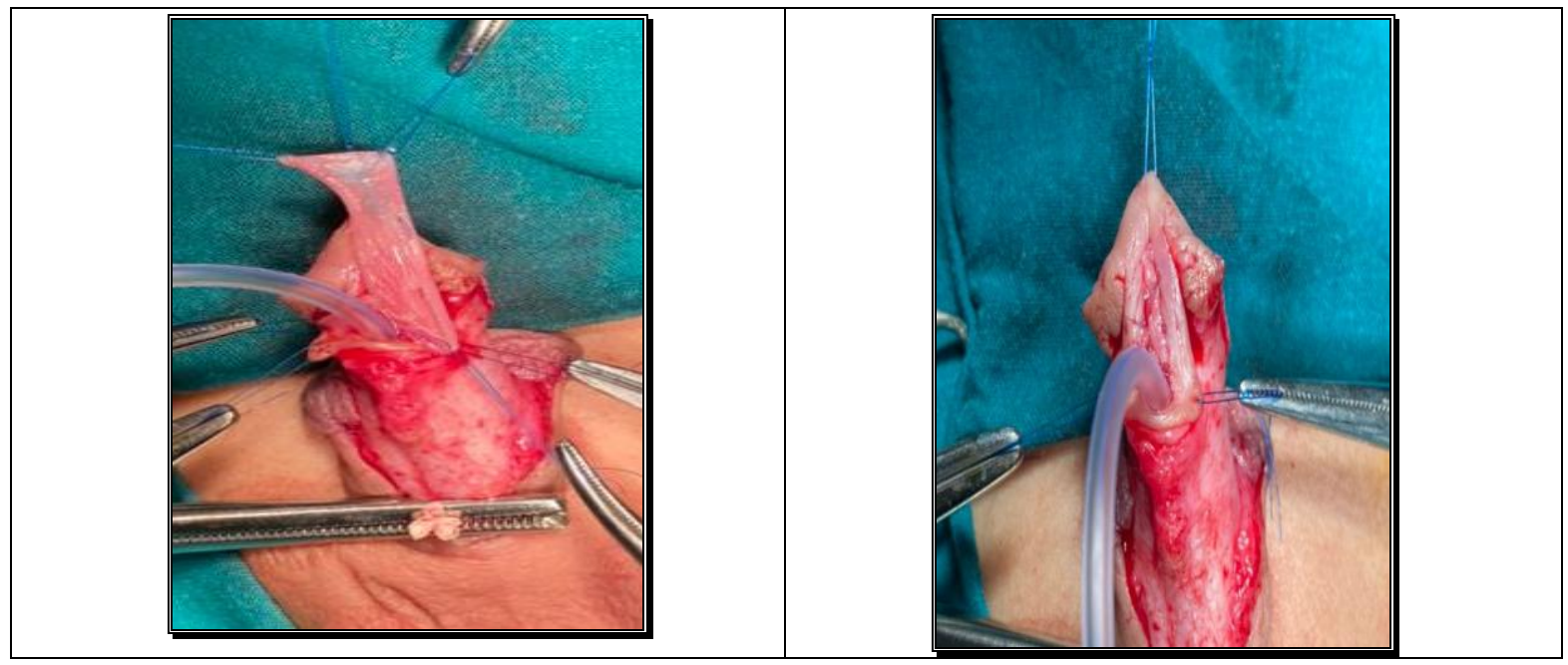

Fig.3

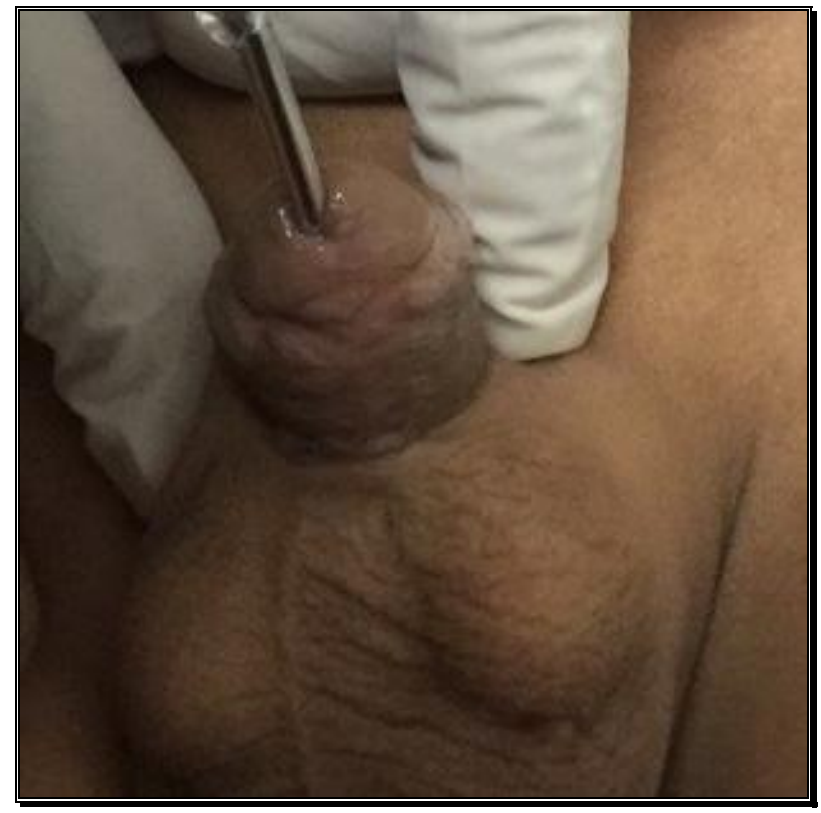


Fig.4 Follow up of Snodgrass case

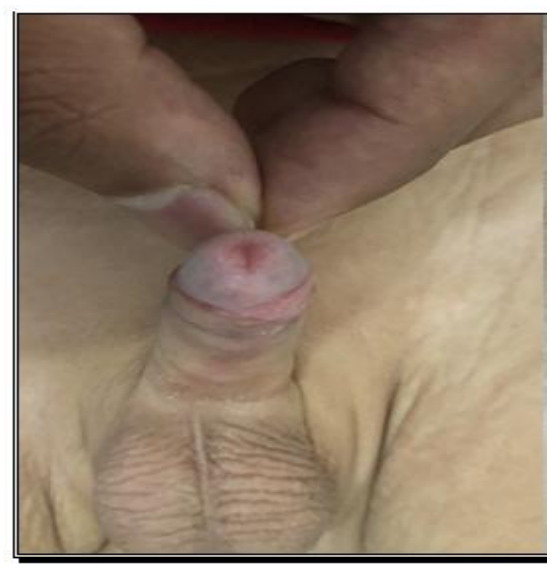

Fig.5 Follow up of Snodgraft case

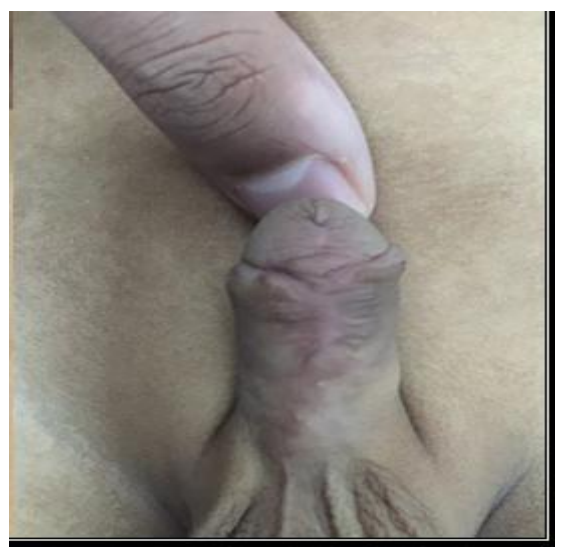

Fig.6 Complications in both groups

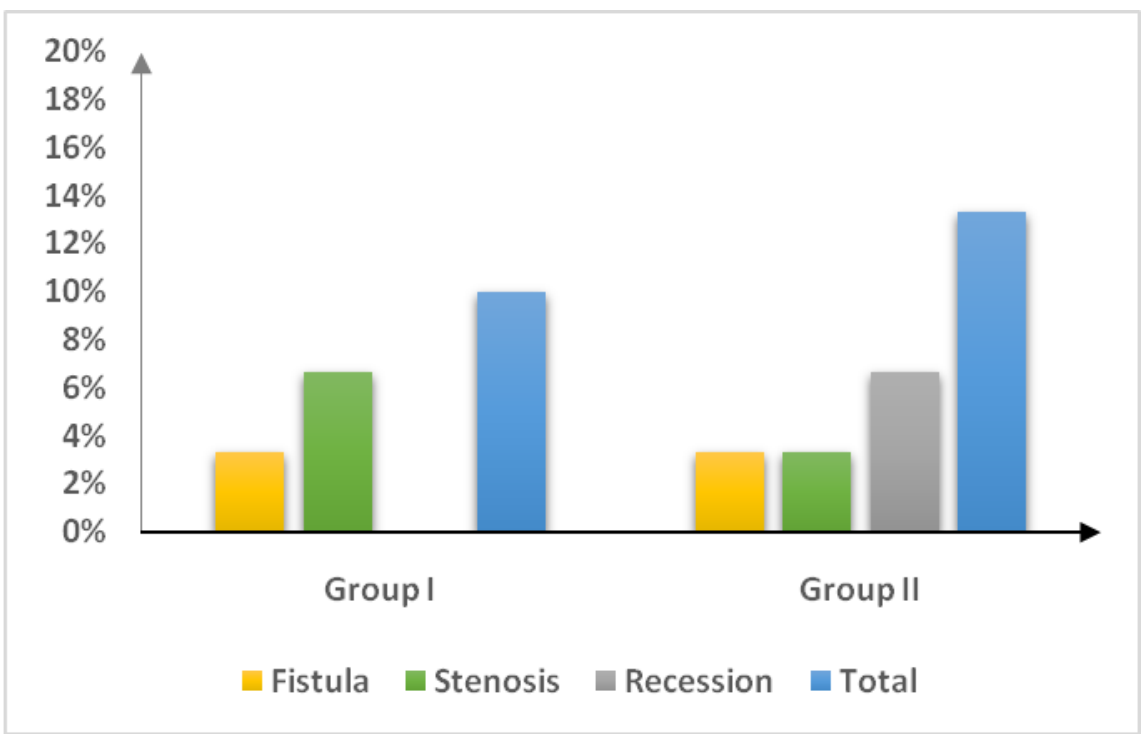

The mean value for operative time in Snodgrass group was $50.07 \pm 7.28$ minutes and in the Snodgraft group, the mean value was $75.47 \pm 9.25$ minutes $(\mathrm{P}$ value $<0.001$ ).

Helmy et al., 2018 reached similar results regarding the operative time in their study. They found out that the only statistically significant difference between both groups was a longer operative time $106 \pm 12 \mathrm{~min}$ in the Snodgraft group compared to only $79 \pm 9$ for Snodgrass group $(\mathrm{p}=0.005)$. As regard to the postoperative evaluation of hypospadias; the process involves many aspects such as repeated follow up to assess surgical outcome, evaluate meatal shape and cosmetic appearance as well as detect any possible complications. Many centers also integrate additional techniques such as uroflowmetry and cystoscopy into their postoperative assessment plan.

In our study we performed uroflowmetry for 4 patients (6.7\% of total cases) including two Snodgraft cases and two Snodgrass cases in order to assess the voiding functions and the 
findings were within the normal range for all the studied cases. However, the technique of uroflowmetry requires toilet trained patients and that obstacle limited our ability of performing the test for all patients included in the study.

Diagnostic cystoscopy was performed for two cases in the Snodgraft group (3.3\% of total cases) to examine the implanted graft, evaluate the urethral condition and detect any possible urethral stricture. Both cases showed viable in place graft with adequate urethral caliber. But unfortunately, cystoscopy is a costly technique that also requires general anesthesia, so not all the patients in the study were examined using this technique.

Complications after hypospadias surgery are frequent, ranging from postoperative infections to complex fistulas and sexual problems. The long-term complication rate may reach up to $54 \%$. There are many factors contributing to these complications such as the severity of the hypospadias and surgeon's experience in addition to child's age during surgery and type of surgery (Dokter et al., 2018).

Meatal stenosis is one of the commonest postoperative complications in hypospadias surgery. It is believed that the reason for meatal stenosis is technical related. It occurs if tubularization of the urethral plate is done too far distally (Pramod and Prakash, 2018).

In this series, stenosis was the most common complication, occurring in $5 \%$ of the children (1 patient in the Snodgrass group and two patients in the Snodgraft group). These patients underwent regular follow up with repeated dilatation using the local anesthetic cream in the outpatient clinic yielding satisfactory results with no need for further operations. Our results were slightly different than findings by Kishk et al., 2018 who had two $(12.5 \%)$ children with meatal stenosis in
Snodgraft group and four $(28.6 \%)$ cases in the Snodgrass group.

The present study results were also differed from outcomes of Smitakahara et al., who studied 100 patients and compared outcomes of50 cases with Graft versus 50 cases with standard TIP procedure. The stenosis rates were lower in Graft group compared to TIP group at a mean follow up of 3.6 years (Silay et al., 2021).

Urethrocutaneous fistula is the second most common complication that has encountered us during this study involving $3.3 \%$ of cases (1 patient in the Snodgrass group and one patient in the Snodgraft group).

The incidence of urethrocutaneous fistula in this study was $3.3 \%$ in the Snodgrass group, keeping with the international incidence of fistula occurring after Snodgrass operation which ranges from 2 to $14 \%$ (Arshadi et al., 2017).

The complication rate of both techniques in our study showed little difference $(10 \%$ in Snodgraft group) to (13.4\% in Snodgraft group) with slightly higher overall complication rate for the Snodgraft technique.

Regarding the complication rate, our findings mirrored the results of a systematic review and metanalysis performed by Alshafei et al., 2020, who analyzed the findings of six studies performed on a total of 617 patients aiming to compare the outcome of Snodgrass and Snodgraft techniques.

In their metanalysis, urethrocutaneous fistula occurred in $9.4 \%(33 / 350)$ of Snodgrass repairs and $4.9 \%(13 / 267)$ of Snodgraft repairs, indicating a slightly higher incidence in Snodgrass repair but without any statistically significant difference $(\mathrm{p}=0.84)$. Meatal/urethral stenosis was reported by all the studies they analyzed, occurring in 53/250 
(21.2\%) Snodgrass repairs and 11/267 (4.1\%) Snodgraft repairs. However, pooled analysis did not show a significant difference between the two groups $(\mathrm{p}=0.12)$.

The success rate in our study was $88.3 \%$ in both groups (90\% in the Snodgraft group and $86.6 \%$ in the Snodgraft group). Success was measured by cosmetically accepted repair, properly functioning neourethra as well as lack of complications.

Snodgraft operation is more technically challenging and requires longer operative time than the original Snodgrass operation, so its indication should be tailored according to the patient condition

Unfortunately, it has been difficult to prove the advantages of the Snodgraft over the Snodgrass repair as they both have low complication rates. So, in order to find out what truly is the better technique, we recommend that studies should include larger number of cases and that the randomization process must be carried out using computerized methods to limit any possible bias.

Therefore, at this point we are faced with a procedure that makes sense but still not proved by evidence and most surgeons adopt it based on expert opinion. We believe that patients with unfavorable plates (narrow and poor spongiosum) may be the ideal candidates for this operation.

\section{References}

Abbas T O, Pippi Salle J L. When to graft the incised plate during TIP repair? A suggested algorithm that may help in the decisionmaking process. Frontiers in pediatrics. 2018 Nov $14 ; 6: 326$.

Abbas T O, Pippi Salle J L. When to graft the incised plate during TIP repair? A suggested algorithm that may help in the decision- making process. Frontiers in pediatrics. 2018 Nov 14;6:326.

Alshafei A, Cascio S, Boland F, O'Shea N, Hickey A, Quinn F. Comparing the outcomes of tubularized incised plate urethroplasty and dorsal inlay graft urethroplasty in children with hypospadias: a systematic review and meta-analysis. Journal of Pediatric Urology. 2020 Jan 22.

Arshadi H, Sabetkish S, Kajbafzadeh A M. Modified tubularized incised plate urethroplasty reduces the risk of fistula and meatal stenosis for proximal hypospadias: a report of 63 cases. International Urology and Nephrology. 2017 Dec 1;49 (12):2099-104.

Chan Y Y, Bury M I, Yura E M, Hofer M D, Cheng E Y, Sharma A K. The current state of tissue engineering in the management of hypospadias. Nature Reviews Urology. 2020 Mar;17(3):162-75.

Chang J, Wang S, Zheng Z. Etiology of Hypospadias: A Comparative Review of Genetic Factors and Developmental Processes Between Human and Animal Models. Research and Reports in Urology. 2020;12:673.

Chen M J, Karaviti L P, Roth D R, Schlomer B J. Birth prevalence of hypospadias and hypospadias risk factors in newborn males in the United States from 1997 to 2012. Journal of pediatric urology. 2018 Oct 1;14(5):425e1.

Cripps S M, Mattiske D M, Black J R, Risbridger G P, Govers L C, Phillips T R, Pask A J. A loss of estrogen signaling in the aromatase deficient mouse penis results in mild hypospadias. Differentiation. 2019 Sep 1;109:42-52.

Dokter E M, Mouës C M, Rooij I A, Biezen J J. Complications after hypospadias correction: prognostic factors and impact on final clinical outcome. Eur J Pediatr Surg. 2018 Apr 1;28(2):200-6.

Hadidi A T. History of hypospadias: Lost in translation. Journal of pediatric surgery. 2017 Feb 1;52(2):211-7.

Helmy T E, Ghanem W, Orban H, Omar H, ElKenawy M, Hafez A T, Dawaba M. Does grafted tubularized incided plate improve the outcome after repair of primary distal hypospadias: A prospective randomized 
study?. Journal of pediatric surgery. 2018 Aug 1;53(8):1461-3.

Keays M A, Dave S. Current hypospadias management: Diagnosis, surgical management, and long-term patient-centred outcomes. Canadian Urological Association Journal. 2017 Jan;11(1-2Suppl1):S48.

Kishk T F, Elsheikh Y M, Elkashty S M, Mansour M R. Comparative study between tabularized incised plate urethroplasty with and without dorsal inlay graft. Menoufia Medical Journal. 2018 Jan 1;31(1):212.

Long C J, Canning D A. Hypospadias: are we as good as we think when we correct proximal hypospadias?. Journal of pediatric urology. 2016 Aug 1;12(4):196-e1.

Maitra S G, Kumar R, Das S K. Distal penile hypospadias repair with Snodgrass and Mathieu procedure: A comparative study. IOSR-JDMS. 2019;18(6):41-2.

Moosa Z Y, AL-hallak Y M. Tunica Vaginalis Flap Versus Inner Preputial Dartos Flap as Waterproof Layer for Proximal Staged Hypospadias Repair: A Comparative Study. Indian Journal of Forensic Medicine \& Toxicology. $2020 \mathrm{Jul} 1 ; 14(3)$.

Nurhadi P, Saputra R A. Profile of hypospadias patients at Saiful Anwar General Hospital Malang. The Pan African Medical Journal. 2018 Jul 11(ARTISSUE).

Pan P. Grafted tabularized incised plate urethroplasty: an excellent option in primary hypospadias with poor urethral plate. International Surgery Journal. 2017 Jun 22;4(7):2270-5.

Pramod S, Prakash G S. Outcome of anterior hypospadias repair: A single center experience. Archives of International Surgery. 2018 Jan 1;8(1):10.

Renaux-Petel M, Mure P Y, Gorduza D B, Mouriquand P. Hypospadias. InPediatric Surgery 2019 (pp. 549-560). Springer, Berlin, Heidelberg.
Salah A N, Mosab I, Mohamed O. Outcome of Snodgrass (Tabularized Incised Plate) in Repair of Primary Distal Hypospadias with Narrow Urethral Plate. The Medical Journal of Cairo University. 2019 Mar 1;87(March):865-9.

Shah H U, Gul H, Khan R, Marwat M. Urethrocutaneous fistula following Snodgrass versus two stage Aivar Bracka repair of distal penile hypospadias in male children: a randomized control trial. Gomal Journal of Medical Sciences. 2018 Jun 30;16(2):54-8.

Silay M S, Bhatt N, Quaedackers J, Bogaert G, Dogan H S, Nijman R J, Rawashdeh Y, Stein $\mathrm{R}$, Tekgul S, Radmayr C. Are there any benefits of using an inlay graft in the treatment of primary hypospadias in children? A systematic review and metanalysis. Journal of Pediatric Urology. 2021 Feb 19.

Springer A, Tekgul S, Subramaniam R. An update of current practice in hypospadias surgery. European Urology Supplements. 2017 Jan $1 ; 16(1): 8-15$.

Thakur D. Outcome of Snodgrass Repair in Distal Hypospadias-An Institutional Experience. Journal of Society of Surgeons of Nepal. 2018;21(2):28-31.

Van der Horst H J, De Wall L L. Hypospadias, all there is to know. European journal of pediatrics. 2017 Apr 1;176(4):435-41.

Zain A Z. Snodgrass urethroplasty for mid and distal penile hypospadias. IRAQI Journal of Medical Sciences. 2017;15(3):283-7.

Zhang Y, Shen Z, Zhou X, Chi Z, Hong X, Huang Y, Huang H, Chen S, Lan K, Lin J, Wu W. Comparison of meatal-based flap (Mathieu) and tabularized incised-plate (TIP) urethroplasties for primary distal hypospadias: A systematic review and metaanalysis. Journal of Pediatric Surgery. 2020 Apr 21.

\section{How to cite this article:}

Wael Omar Zeina, Ahmed Medhat Zaki, Osama Abdel-Ellah Al-Najjar, Ehab Abd El Aziz El Shafei and Mohamed Abdel-Sattar Mohamed. 2021. Snodgraft Versus Snodgrass Repair of Primary Distal Hypospadias: A Comparative Study. Int.J.Curr.Microbiol.App.Sci. 10(05): 512523. doi: https://doi.org/10.20546/ijcmas.2021.1005.059 